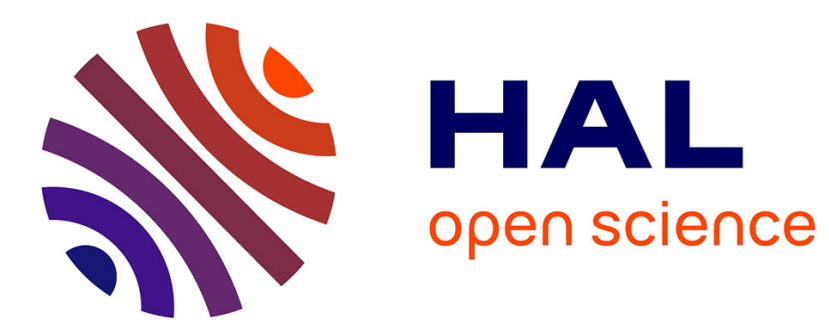

\title{
Multimodal Hyperbole
}

Gaëlle Ferré

\section{To cite this version:}

Gaëlle Ferré. Multimodal Hyperbole. Multimodal Communication, 2014, 3 (1), pp.25-50. 10.1515/mc-2014-0003 . hal-01422552

\section{HAL Id: hal-01422552 https://hal.science/hal-01422552}

Submitted on 26 Dec 2016

HAL is a multi-disciplinary open access archive for the deposit and dissemination of scientific research documents, whether they are published or not. The documents may come from teaching and research institutions in France or abroad, or from public or private research centers.
L'archive ouverte pluridisciplinaire HAL, est destinée au dépôt et à la diffusion de documents scientifiques de niveau recherche, publiés ou non, émanant des établissements d'enseignement et de recherche français ou étrangers, des laboratoires publics ou privés. 


\title{
Multimodal Hyperbole
}

Gaëlle Ferré

LLING, Université de Nantes

Chemin de la Censive du Tertre BP 81227, 44312 Nantes cedex 3, France

Gaelle.Ferre@univ-nantes.fr

\begin{abstract}
This paper presents a study of hyperbole in the framework of Multimodal Discourse Analysis, based on video recordings of conversational English. Hyperbole is a figure of speech used to express exaggerated statements which do not correspond to reality but which are nevertheless not perceived as lies. Hyperbole opens up a discourse frame and establishes a new focus on information in speech making that piece of information more salient than surrounding discourse. The emphasis thus created thanks to various semantic-syntactic processes is reflected in prosody and gesture with the use of focalization devices. At last, prosodic patterns and gestures do not only reinforce verbal emphasis, they may fully contribute to the emphasis in a complementary way, and even constitute hyperbolic communicative acts by themselves. In the conclusion, we propose that hyperbole is used by speakers to construct an individual, intersubjective identity element.
\end{abstract}

Keywords

Hyperbole, Multimodal Discourse Analysis, prosodic and gestural enactments

\section{Introduction}

In my research so far, I have been particularly interested in the expression of focus in speech, a term which has been assigned different meanings in the literature depending on the field of study of the authors. Prévost (2003: 99) summarizes the three main acceptations of 'focus' as corresponding to some:

- 'prosodic emphasis', i.e. the element that stands out prosodically speaking in the utterance,

- 'informative state', i.e. the element in focus bears the new information in the utterance,

- 'cognitive state', i.e. the element in focus is the most active element in the mental representation of the speaker.

The first two definitions apply mainly to the local, utterance level, which was the domain of my previous work on 'markedness' and 'scalarity' respectively (Ferré, 2004, 2011, 2014). If scalarity can be conceived of at the local level of the utterance, with the use by speakers of degree adverbs for instance and what Pomerantz (1986) more generally terms 'extreme case formulations', it can also be understood at a more global, discourse level of organization, revealing the 'cognitive state' of speakers as described in the last definition given above. Hyperbole, which can be generally defined as exaggeration and which therefore involves some degree scale, 'inflates the discrepancy between what was expected and what ensues via an overstated description of what happened' (Colston and Keller, 1998: 500), and establishes a new focus on information in the speaker's discourse making that piece of information more salient than surrounding discourse. 'Emphasis being an automatic effect of hyperbole' (Claridge, 2010: 12), this makes the study of hyperbole of particular interest to me. 
As will be seen in Section 1, which presents the theoretical background of this study, hyperbole has been the object of studies in pragmatics (Claridge, 2010; McCarthy and Carter, 2004; Norrick, 2004; Pomerantz, 1986, to quote the major works on the topic). All of the studies examined hyperbole (or related phenomena) in written texts or in transcripts of spoken corpora, with little to no access to oral or visual features. The present study views hyperbole from a slightly different perspective. Drawing on a corpus of video-taped interactions of spoken English, hyperbole is described in the framework of Multimodal Discourse Analysis (MDA), as well as the gesture studies developed by Kendon (2004) and McNeill (1992; 2005). MDA considers face-to-face communication as a multi-layered ensemble of actions, that involves articulatory movements for speech and intonation, but also other body movements triggered by the communicative intentions of the individual. As presented in the Radial Model of face-to-face communication (Ferré, 2014), each of these actions reveals the mental processes at stake in any 'communicative act', a term coined by Wee (2004: 2162), who considers 'communicative act as a broader term than speech act. While speech act is understood to specifically involve linguistic communication (...), communicative act encompasses both linguistic and non-linguistic communication'. The mental processes are organized in 5 modules: the pragmatic, lexical, grammatical, prosodic and phonological modules which interact with one another in a circular way. Communicative acts are triggered by and have an impact on the physical external world which is itself modulated by the individuals' representations of the world. This is important as we will see that hyperbole always involves representations.

After a brief presentation of the corpus in Section 2, it will be shown in a qualitative analysis rather than a quantitative one, that hyperbole presents features of unexpectedness at the textual level (Section 3) and that this unexpectedness is also marked in other modes than the verbal one. In prosody, hyperbole is marked with particular rhythmic, emphatic properties (Sections 4.1 and 4.2), but prosody itself can be hyperbolic in certain sequences of reported speech and be considered as hyperbolic prosodic enactments (Section 4.3.). Unexpectedness is also reflected in the gestures made by the participants. These can be focalization gestures which accompany emphatic stresses in verbal hyperboles (Section 5.1) as well as gestures which are not hyperbolic by nature but which do contribute to the reinforcement of hyperbolic speech (Section 5.2). And much in the same way as what is observed for prosody, gestures can present hyperbolic features in their form and either accompany and reinforce hyperbolic speech or stand alone as hyperbolic gestural enactments (Section 5.3). Hyperbole can then be graded in terms of its degrees of communicative dynamism depending on the material carriers involved, with some forms more predictable than others (section 6). In the conclusion, I will say a brief word on the participation of hyperbolic 'communicative acts' to the construction of identity for participants.

\section{Theoretical background 1.1. Definition of hyperbole}

To start with as broad a term as possible, 'exaggeration' has been the object of a certain numbers of studies in the literature at the 'semantics-pragmatics interface' (Claridge, 2010: 5). Basing their work on different types of corpora (fiction, newspaper articles, conversation transcripts, mostly), authors found that exaggeration can take three different forms: 'Extreme Case Formulations' (ECFs), simple overstatements and hyperboles.

- Extreme Case Formulations (ECFs) 
Extreme Case Formulations were first described by Pomerantz (1986). When producing this type of exaggeration, speakers use adverbs, adjectives (often in the superlative form) or nouns that express an extreme degree of a quantity or quality. Example (1) shows an ECF taken from my corpus ${ }^{1}$ :

(1) I like simple salads. The best salads ever is Galician salads.

The statement 'the best salads ever is Galician salads' in this example can be considered as a case of exaggeration because of the fact that it expresses a personal and subjective judgment on what type of salad is the best one. Needless to say that any individual could be of a different opinion and that this is intended as a non-factual statement. There is no objective reason why Galician salads should be better to eat than any other.

- Overstatements

McCarthy \& Carter (2004), as well as Norrick (2004) distinguish overstatements from ECFs, although the former also imply some degree scale. 'Overstatement more generally includes any extravagant statement of amplification or attenuation used to express emotion and not to be taken literally' (Norrick, 2004: 1728). Although overstatements are often in collocation with ECFs, they do not necessarily include them. For instance, the utterance in example (2) below does not include any ECF. Yet, the context in which it was uttered makes it sound exaggerated if not even completely doubtful. Tom, in my corpus, describes how he and his friends used to skate at a gym which was then refurbished with a new carpet that made skating difficult and even impossible.

We'd been crying, no no. Don't do it, don't do it.

Based on common knowledge on how refurbishing is managed by the authorities in a sports facility, it is doubtful that the boys had their word to say. Even if it had been the case, we can also doubt that they would have had any idea at the time of the fact that skating would not be possible anymore. And at last, if they could say something, they probably didn't 'cry'.

- Hyperbole

Although Claridge (op.cit.) does not make any distinction between ECFs, overstatements and hyperbole, the latter discourse phenomenon is distinguished from the other two by other authors. Norrick, quoting Preminger (1974), defines it as 'a figure or trope of bold exaggeration' (2004: 1728), and notes that hyperbole was already an object of study in classical rhetoric. Norrick considers ECFs and overstatements as sub-categories of hyperbole. This corresponds to the general definition of hyperbole found in the OED, which applies equally to the three terms found in the literature: 'A figure of speech consisting in exaggerated or extravagant statement, used to express strong feeling or produce a strong impression and not meant to be taken literally.' In the present paper on hyperbole, ECFs will not be considered, but overstatements will, as weaker cases of hyperbolic speech (without any distinction in treatment though). Hyperbole most of the time implies some sort of comparison used to reinforce the degree of a quantity or a quality. Besides, Cano Mora (2004: 14) notes that hyperbole 'is by far the trope that most often co-occurs with other figures'. In my corpus for instance, Kate describes her hair as 'poker-straight', i.e. 'as straight as a poker', in example (3):

\footnotetext{
${ }^{1}$ Examples from my corpus are transcribed using Sacks et al.'s transcription conventions (1974). Punctuation reflects intonation patterns and contours. The corpus itself is described in Section 2.
} 
(3) Anyway it's like really poker-straight, and I don't like it.

Claridge (2010: 100) distinguishes between conventional, semi-creative (or semiconventional) and creative hyperbole. Example (3) affords a typical instance of conventional hyperbole, 'poker-straight' being the set-phrase to describe straight hair, especially when this quality is judged as negative. In the corpus, one of the participants describes clothes as 'fuddy duddy granny stuff' (an example described in more detail in Section 4.1 on rhythm). The phrase is semi-conventional because of the addition of 'granny' to the set-phrase 'fuddy duddy' which means 'conservative' or 'dull'. The whole phrase then can be understood as closer in meaning to 'extremely old-fashioned'. When the same speaker however asks her friend: 'Did you feel like a right charity case being passed around all the families?' and then calls her 'spare part', she shows more creativity. A creative hyperbole has a greater impact in terms of degree.

\subsection{Hyperbole and scalarity}

The notion of hyperbole implies an underlying degree scale since it means that the listener who judges an utterance as an exaggeration thinks that some degree expressed in this utterance is too high (be it negative or positive). Yet, there are different kinds of degrees.

As Sapir puts it: 'Every quantifiable, whether existent (say house) or occurrent (say run) or quality of existent (say red) or quality of occurrent (say gracefully), is intrinsically gradable (...) even if that quantifiable is not yet explicitly quantified' (1944: 94), e.g. by the use of a quantifier or an intensifier.

Gradability is furthermore linked to the notion of implicit or explicit comparison: if I say of a house that it is big, it implicitly means that I compare this house with other houses in my own experience. There are however two distinct comparisons which can be made: (a) gradability can be expressed in comparison to some kind of 'norm' or 'standard', or (b) gradability can be context-dependent. For instance, if I say of a person who is 100 years that the person is old, the gradation I make is based on the fact that most people don't live up to this age, therefore, I implicitly compare the person's age to some 'standard' (average) old age. This is not context-dependent insofar as most people would agree with me that 100 years is old for a human being. This kind of adjective is described by Kennedy (2002) as 'ABSOLUTE (gradable) adjectives'. These are opposed to 'RELATIVE (gradable) adjectives', that is to say adjectives which express a context-dependent gradation. Kennedy explains this distinction with the following example:

(4) The Mars Pathfinder mission was expensive. (from Kennedy, 2002: 1)

'The 'Mars Pathfinder mission' may be considered as expensive by people like you and me, but if compared to other missions, it was not expensive at all.' (Kennedy, op. cit.)

At last, Kennedy distinguishes two different kinds of adjectives among the absolute gradable adjectives, but I believe this distinction could apply to relative gradable adjectives as well. Some are what he terms minimum standard adjectives, that is to say adjectives which 'simply require their arguments to possess some minimal degree of the property they describe' (op. cit., p. 4):

The table is wet. 
These adjectives are opposed to the maximum standard adjectives, which 'are similar, except that their arguments are required to possess a maximal degree in the property in question' (op. cit., p. 5):

The glass is full.

The notions of a maximum and a minimum have been widely used in the literature on scalarity although sometimes with researchers using different grading scales, as for instance Ducrot (1980) who rather emphasizes on a continuum of a doubly-oriented scale: a scale which possesses a negative and a positive orientation (see also Israel (2006) and Herrero Ruiz (2008) on the question of degree scales in the case of over- and understatements). This is how it works in an example from my own corpus:

(7) She felt really awful and I felt extra awful.

Example (7) can be analyzed in the following way on a grading scale:

\begin{tabular}{l|ll} 
good & bad & $<$ awful $<$ really awful $<$ extra awful \\
\hline positive & less negative
\end{tabular}

The same scale can be applied to the examples given by Kennedy above, but the judgment is going to be context-dependent, which means that a change in gradability is operated here: the fact that the table is wet is going to be judged negative if the table is meant to be used for some activity that requires it to be dry (e.g. writing), but it may as well be judged as positive if the fact that this table is wet is meant as a proof of it just having been cleaned, for instance. The same can be said of example (6), which can be judged positive if someone wants to drink the content of the glass (as in a glass full of beer provided the person likes beer and is particularly desirous of it at the moment of enunciation), but it can also be judged as highly negative if the content is some particularly distasteful medecine. So we can say that this kind of scalar analysis is extremely close to what Sapir (1944) calls affect, insofar as it involves judgment. In his paper, Sapir concentrates on quantifiers, but this remark applies as well to other kinds of grading: "they [quantifiers] unavoidably color the judgment with their latent affect of approval or disapproval (e.g. "as much as" smuggles in a note of satisfaction; "only" and "hardly" tend to voice disappointment)' (1944: 108). So to summarize what we have seen so far, there are two distinct scales for grading from the speaker's point of view, one is a rather objective scale, and it corresponds to Kennedy's description of scalarity, and the second one, used by Ducrot and Sapir, is a more subjective scale since it reveals the speaker's stance (satisfaction or disappointment) towards speech content, and we will see that hyperbole makes use of both scales, which explains why hyperbole has both a quantitative and an evaluative function as described in Section 1.1.

\subsection{Hyperbole identification and production contexts}

The major challenge in discourse is to identify hyperbolic speech without any prior knowledge of the text producers. McCarthy and Carter (op. cit.: 162-163) provide a list of the pragmatic features that characterize hyperbole and which are presented in a slightly different order here: 
- Hyperbolic speech presents a disjunction with context: 'the speaker's utterance seems at odds with the general context. This is completed by Claridge (2010: 38) who adds further that hyperbole is at odds 'in the given situation/in the light of common world knowledge and expectations about the 'normal' state of affairs, as seen by an 'objective observer'.

- Although hyperbole distorts reality, it is not intended to deceive and is not perceived as a lie by listeners.

- Hyperbole is generally accepted without challenge and even supported by listeners (by further contribution or by laughter). Yet, we see in Claridge (op. cit.) that listeners may sometimes challenge the exaggeration and speakers may acknowledge that the real state of affairs is not as extreme as first depicted.

- Speakers and listeners (if not challenging) engage in the co-construction of fictitious worlds where impossible, exaggerated events take place.

- In spite of the distortion between context/co-text and hyperbolic speech, the utterance is perceived as relevant to the speech act being performed.

Still following McCarthy and Carter's description, the pragmatic features listed above show the formal textual characteristics:

- Hyperbole is notable thanks to shifts in footing, marked for instance by the use of specific discourse markers (Fraser, 1999), in conversational frames. For instance, Sert (2008: 6) noted that 'narrative shift markers (suddenly) were very common within the linguistic environment of hyperboles.'

- Hyperbole is expressed in the most extreme way being in collocation with ECFs and other processes of intensification.

- Hyperbole is supported by syntactic devices like polysyndeton (e.g. loads and loads) and complex modification (e.g. really great big long pole).

For Cano Mora (2009: 33), hyperbole serves both a quantitative function, insofar as 'the quantity or value, whether positive or negative, of an objective fact is subjectively inflated or deflated in varying degrees but always to excess' and a qualitative function, as an evaluative resource (McCarthy and Carter, 2004: 170). Although hyperbole has been especially noted in argumentation (Pomerantz, 1986), strengthening the force of the arguments, and narration (and especially in story punch lines (Christodoulidou, 2011) which often present a strong evaluative dimension), McCarthy and Carter (op. cit.: 177) note that hyperbole also occurs in many other discourse types, humorous or not. For the two authors, they are not related to any specific type of relationship between participants, or to particular discourse genres, but may occur in a vast array of contexts.

\section{Corpus and methodology}

The corpus used for this study is the English Video Corpus (ENVID) which is still under construction and consists in a collection of dialogues. It includes videos recorded by myself and Master students. Each dialogue was recorded in sound-attenuated rooms at different universities, to provide good sound quality for prosodic treatment, and lasts half an hour. The participants were all British and aged 20 to 23. The two participants in each pair were friends and were just asked to chat as they usually do in ordinary life without any further instructions. They were told they participated in studies in linguistics, but no mention was made of prosody or gesture. 4 dialogues were selected for the present study on hyperbole (which makes 2 hours 
of interaction between 8 speakers of 22.774 words). This might sound a small collection but the aim of the present paper is to provide a qualitative analysis rather than a quantitative one.

The dialogues were all transcribed manually using PRAAT (Boersma and Weenink, 2009), speech being aligned with sound at the level of the Intonation Phrase as defined by Selkirk (1995) and Wells (2006). This prosodic unit corresponds to what Pierrehumbert and Hirschberg (1990) name Intermediate Phrase. Part of the corpus is also aligned at word and phoneme level. This alignment was obtained automatically with SPPAS (Bigi, 2012) and corrected manually. The phonemic transcription uses SAMPA (Wells, 1997) instead of the International Phonetic Alphabet to avoid compatibility problems in between tools.

At last, gestures were transcribed in ELAN (Wittenburg et al., 2006) for parts of the corpus after importing Praat's speech tracks for a better vizualization of gesture-speech alignment. This transcription includes gaze direction, head and eyebrow movements as well as hand gestures. Hand gestures are transcribed in two different tracks for each participant: a first track is devoted to the formal description of the gesture (hand shape, hand position, single or double-handed gesture, movement type and direction). The second track transcribes the functional relationship between speech and gesture, using McNeill's typology (1992, 2005). It includes the following functions: beat, deictic, emblem, iconic, metaphoric, butterworth and adaptor. When a gesture has two dimensions, the main dimension is noted in this track and the secondary dimension noted in a separate track.

Hyperbolic utterances or sequences in the corpus were identified watching the video files (so as not to consider a priori that hyperbole could only be present in speech) and noted on the written transcript of each interaction. Hyperbolic passages were then individually analyzed using PRAAT and ELAN.

\section{Verbal hyperbole}

\subsection{Lexical hyperbole}

As far as the lexicon is concerned, two different processes are used by the participants in the corpus. The first kind of hyperbole, which is not met as often as the other, consists in using a word which is very close or equals the maximal degree on the scale corresponding to this context. It has been described before in the literature and differs from ECFs. Let's have a look at the three following examples:

(8) I hate to speak to people that I don't know that well.

(9) My dad used to teach in Hebburn when he first started teaching. He used to get harassed by all the pupils.

(10) She met my dad and then got whizzed off to so many different countries.

Example (8) offers the perfect illustration of a maximal degree on the scale of liking/disliking. 'Love' would be the maximal positive degree, whereas 'hate' is the maximal negative one. In between are other degrees such as 'not quite like' for instance. It then appears that 'hate' seems a bit strong semantically speaking in this particular context in which the speaker is just explaining how she had to 'be polite' and speak to people who invited her home for a weekend. It seems all the more strong as she doesn't express negative feelings towards these people in the preceding context, only that she would have preferred to spend more time on her own. Yet, this overstatement is highly conventional which reduces its force. 
In (9), the same speaker explains how Hebburn is a rough town. Again, she uses quite a strong word to illustrate this point of view, e.g. 'harass'. The difference with the preceding example is that the preceding context here prefaces a strong word to come. One might however have expected some other utterance such as 'the pupils used to mess around quite a bit'. The effect produced by the use of 'harass' is not only one of a strong word, but also a word which focuses on the father as patient of the predication.

In (10), 'whizzed off' is highly unexpected in this context, and again a strong formulation. The other speaker is explaining how her parents met, and how they had been travelling from one country to another. Exactly as in the preceding example, the mother is seen as patient of the predication. But the use of 'whizzed off' contains two inherent semantic features which are interesting: first, a notion of great speed, and second, deriving from this speed, a kind of whistling noise. I believe this is the kind of verb that would be used for a stone tied to a rope and thrown away at great speed. This is certainly unusual to use this verb for an individual who would not be able to be moving quickly enough to make this noise. It dramatizes the explanation much and is probably inspired from cartoons.

The second kind of lexical hyperbole consists in changing the predicate to another one that doesn't belong to the same category and which is thus highly unexpected in that context.

(11) It was as if it would leap off the wall and like latch itself onto my leg and start gnawing me.

(12) They anaesthetize them and they just start chomping.

(13) He'd get really excited. He'd start ripping shreds off his hum present.

(14) I went into the shop and we cleared the shelves out.

Examples (11) and (12) reveal exactly the same process: both utterances are spoken by the same speaker at two different times in the dialogue when she was speaking of 'spiders'. The two verbs are unexpected since spiders happen to bite, but they do not 'gnaw' or 'chomp'. Actually, the predicate 'bite' shows an atomic telic event. 'Atomic telic events are based on a holistic, 'one step' change-of-state [...]. They involve only two degrees, i.e. a minimal degree and a maximal one. On the contrary, non-atomic telic events are based on a complex changeof-state, possessing intermediary degrees between the minimal and the maximal degree' (Caudal and Nicolas, 2005: 278): either the spider bites or it doesn't, the process can't last unless it is repeated. On the contrary, 'gnaw' and 'chomp' imply a mastication process, and both predicates reveal non-atomic telic events: the mastication process is a gradual one that will lead to complete grinding if it is sustained. So both verbs emphasize the action at stake in this context which is furthermore underlined by the use of the progressive form (-ing). It renders the picturing of that action more vivid.

Action is emphasized as well in (13). One of the speakers is telling her friend about a joke she and her other brothers and sisters used to make to her younger brother at Christmas: they used to give him a lousy present. For a present, one would probably use 'unpack' or 'open', that is an atomic telic event, whereas 'rip shreds off' is a non-atomic telic event focusing on the process of unpacking which is qualified as 'in an excited manner', both in the preceding discourse and in this idiomatic phrase.

Example (14) shows a reverse process. Instead of focusing on the action, as would have been expected, it focuses on the result of the action. The speaker is telling about 'cheap huge punnets of strawberries sold at Marks and Spencer's once' and where one would have 
expected 'we bought so many' or 'we took so many', that is some kind of action, the speaker instead concentrates on the state of the shelves which were left empty after they went into the shop and this is rendered by the particle 'out' in 'clear out'. I will also show in Section 5.3 that this utterance is accompanied by a large gesture that emphasizes it once more.

\subsection{Hyperbole at discourse level}

As seen above, hyperbole can occur at very local, lexical level. We have also seen in Section 1.2 that some statements could be considered as hyperbolic not really in the words used but rather in the interpretation given by a speaker of a certain context.

(15) David had always waited for me at the station, so to arrive at the station and suddenly have no one waiting for me, that would have been the worst thing in the world.

(16) Oh that's cruel. That is so cruel.

(17) God. Nearly killed me.

(18) Yes, I guess they can. They get hold of your leg, you get gangrene afterwards.

In order to understand these five examples, one has to take into account the conversational context in which they appear. In (15), the speaker is telling her friend how difficult it was the last time she came to France, since her boyfriend David was not in Nantes anymore. In other words, she was not particularly happy to come back to this town on her own, and a woman friend of hers had proposed to come and pick her up at the station, for which she was grateful. She nonetheless imagines what it would have been like to arrive in Nantes and be on her own and evaluates this as 'the worst thing in the world'. This sounds extreme when one considers the context, since it seems that there are a great many other things which could be qualified as 'worst thing in the world' on a more general scale.

Example (16) comes as the evaluation proposed by one of the speakers after her friend has been telling her a joke that she and her other brothers or sisters used to make to her younger brother at Christmas. The joke consisted in offering him a lousy present (an old shoe, etc). Again, the notion of cruelty seems a bit strong in this particular context. The utterance rather serves as an interactional means to express empathy with the first speaker who had announced she and her siblings used to 'do this terrible thing at Christmas', so the evaluation as 'cruel' shows that the story told by the first speaker has been efficient and has reached the prefaced aim: 'tell something terrible'.

Example (17) is also the evaluation of a narrative, but it is expressed by the narrator this time. The speaker told her partner in the interaction how she had a difficult time when she was living in La Rochelle, a French town, and her boyfriend was living in Nantes, another French town three hours by train from La Rochelle. She used to come to Nantes some weekends but her schedule was really tight then and she had to get up extremely early. Although this idiomatic phrase is quite used in English, it is relevant that it comes in the evaluation of the narrative here because of the use of 'kill' which can also be qualified as expressing some maximal degree on the scale of exhaustion. Claridge (2010) mentions that the semantic field related to 'death' is very hyperbole prone ${ }^{2}$.

In (18), the same speaker as the one telling the preceding example has told a narrative on some seemingly carnivorous spiders in Saudi Arabia, which are a danger for camels. Her

\footnotetext{
${ }^{2}$ The semantic field of 'death' will also be referred to in examples (26) and (29) later in the paper with the mention by two speakers of 'heaven' and 'banshee'.
} 
friend has just been asking if they could 'do that to people as well' and she answers that they probably can. She then adds this utterance which is mere speculation but nevertheless shows how she jumps to the worst possible scenario in her narrative. It is precisely the fact that the speaker has no real idea of the truth of this statement (the statement is immediately preceded by 'yes I guess they can') that makes it particularly extreme since it gives precise details on how horrible the situation would be. What is particularly interesting is that, whereas examples (15), (16) and (17) all contain ECFs, this is absolutely not the case here. The hyperbole functions solely on the fact that gangrene is considered as some extreme infection that can lead to amputation.

\section{Hyperbole and prosody 4.1. Rhythm}

As far as rhythm is concerned, hyperbolic speech tends to be quite spasmodic on two accounts: first because of the repetition of certain sounds in an utterance, but also because of the use of focalization pauses. The speakers in my corpus make quite a large use of alliterations and assonances in their speech, e.g. repetition of a sound in a single utterance. Here are a few examples of these alliterations (some of which were quoted in previous sections but are reproduced here for the sake of clarity):

(20) They get hold of your leg, you get gangrene afterwards.

(21) That would have been the worst thing in the world.

It's all (h) (0.3) fuddy duddy granny stuff.

Whereas examples (19) and (20) consist in a multiple repetition of a single consonant, the other examples show a single repetition of a sound sequence (that is more than one sound is repeated) as in (21), or for (22), the repetition of several sounds, so that perceptively, this amounts to the same impression of overload. The effect of the repetition is to make a syllable more prominent whereas it would otherwise go unnoticed being unaccented: the same sound comes at regular intervals of time thus making some sort of rhythmic beat. Example (22) is interesting since the phrase 'fuddy duddy' is rather conventional (although already based on sound repetition), but the addition by the speaker of 'granny' and 'stuff' overloads the phrase with sound repetition.

In these examples, focalization pauses (in seconds) are indicated in brackets. Focalization pauses are distinguished from hesitation pauses and syntactic pauses. They typically precede a syllable with a strong degree of stress (emphatic stress), are in no way associated with fillers (like 'er, hem'), and do not occur at a Transition Relevance Place (Sacks et al., 1974). They can be both silent or audible in-breaths. The major difference between hesitation and focalization pauses is a rhythmic one: in the case of hesitation pauses, speech rate is slower before the pause than after it and it is exactly the contrary in the case of focalization pauses. This means that speakers have a slower speech rate on the focalized item as they want this item to stand out from the rest of their speech. Focalization pauses are used by speakers each time they introduce a disjunction in their speech, and this disjunction can be created either by the use of an unexpected word or by code-switching or even by a change of language register when they use a highly specific word. They occur in many contexts, but hyperboles favour the use of focalization pauses. In example (22), one can see that the unexpected phrase 'fuddy 
duddy granny stuff' (supposed to describe clothes in a shop), which contains the sound repetitions is also preceded both by an audible in-breath and a silent pause. Here is another example:

They're like (0.2) thick and (0.1) squishy like marshmallows.

The two focalization pauses here put emphasis on both 'thick' and 'squishy' but they are also a means for the speaker to warn the listener that something unusual is going to be said, that a disjunction is going to be made between what precedes and what follows. The present description of scallops is indeed hardly expected and the comparison with marshmallows is hyperbolic since marshmallows constitute some particularly good representative of 'squishy' material.

\subsection{Prosodic properties of hyperbole}

Whereas Extreme Case Formulations are most of the time unmarked prosodically speaking, this is not the case of hyperbole which attracts emphatic patterns. The emphasis is expressed by syllable lengthening - especially of the initial consonant of the word that carries the emphasis - , as well as a peak in intensity and fundamental frequency (although this last parameter is less regular). Let's have a look at a previous example repeated here for the sake of clarity:

(24) It was as if it was gonna (h) leap off the (0.3) wa:ll and (0.4) like (0.1) la:tch itself onto my le:g and start gnaw:ing me.

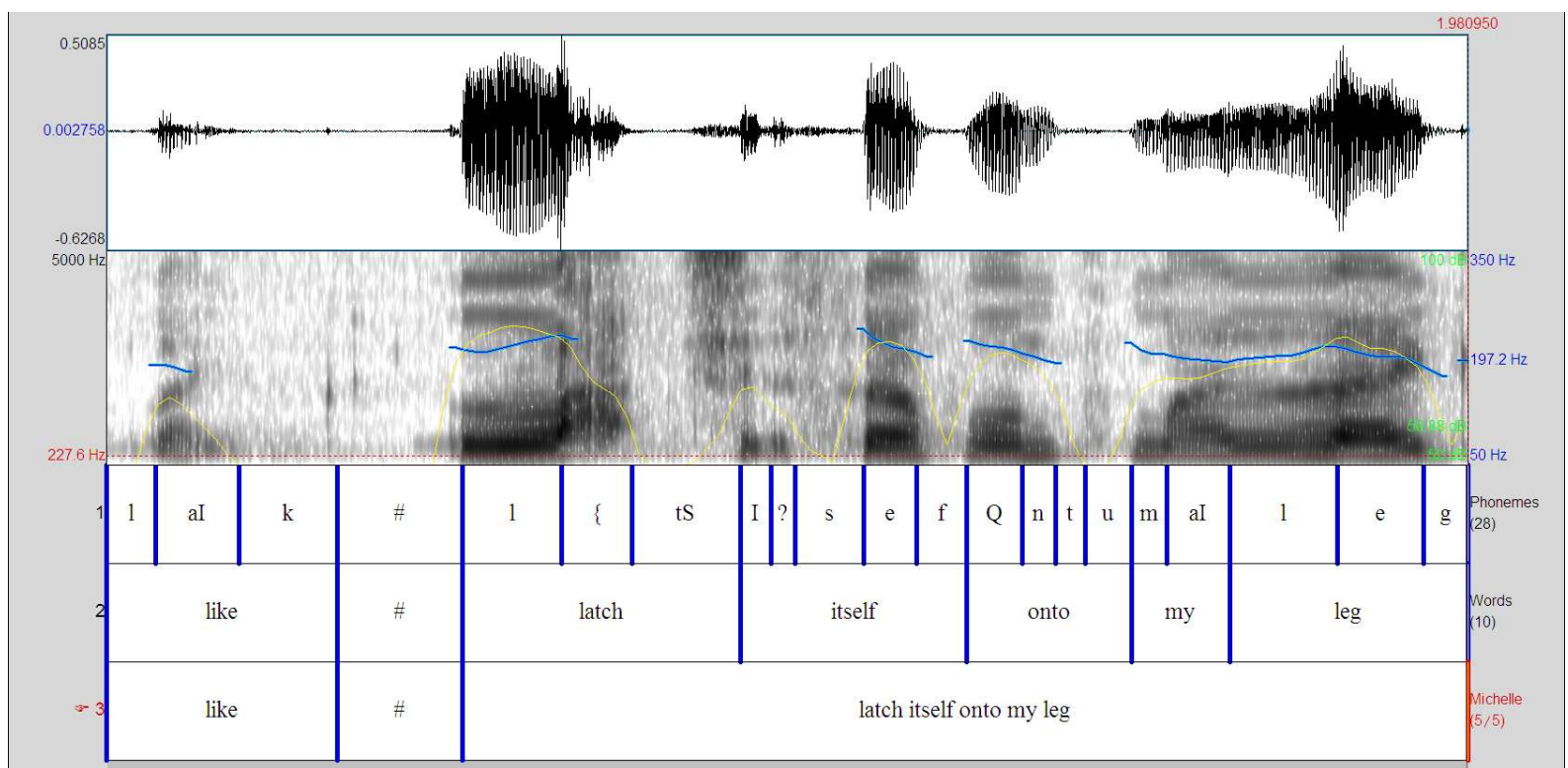

Figure 1. Praat window showing the waveform (top), the spectrogram together with the pitch track in blue and intensity curve in yellow (middle part), and utterance transcription in phonemes, words and Intonation Phrases (bottom part) of "like \# latch itself onto my leg"

Only part of the utterance is shown in Figure 1 where we can see that both 'latch' and 'leg' are lengthened. Whereas 'latch' has a long initial consonant /1/ (1.7 times longer than the mean /1/ consonant for this speaker), both the initial consonant /1/ of 'leg' and the vowel /e/ are extended (by 1.8 and 1.9 times respectively). Both words are uttered with a strong intensity peak, but in this example, intonation is not extremely modulated. The effect of the 
lengthening of the two syllables and of the intensity peaks is to create an accentual arch in the Intonation Phrase with two strong stresses at the beginning and end of the phrase which contributes to making it stand out from the adjacent discourse.

In example (25) below, another participant is talking about two characters in a film and the beginning of her speech turn is particularly emphatic as shown in Figure 2. The first syllable of 'horrible' is lengthened with the /o:/ 1.6 longer than the same vowel uttered by the speaker in other phrases. Although the lengthening is not as important as the one in the previous example if we compare the sounds to the mean duration of the same sounds for the time of the conversation, it is made perceptually salient with the acceleration of the speech rate on the subsequent syllables in the phrase. There is also an intensity peak on the syllable /ho:/ but this time, it is accompanied by a step-up in pitch that was not present in example (24). Later in the example, 'pathos' is also lengthened being 2.3 times longer than the sum of the mean duration of its separate sounds in the rest of the conversation for this speaker, although all the sounds in the word are lengthened. It is preceded by a focalization pause, although it shows no peak in intensity or fundamental frequency.

(25) Yeah (0.1) she's ho:rrible to her and then uh (0.1) it's really kind of like (0.2) pa:tho:s, when you saw her mother's face, because she just treated her so badly.

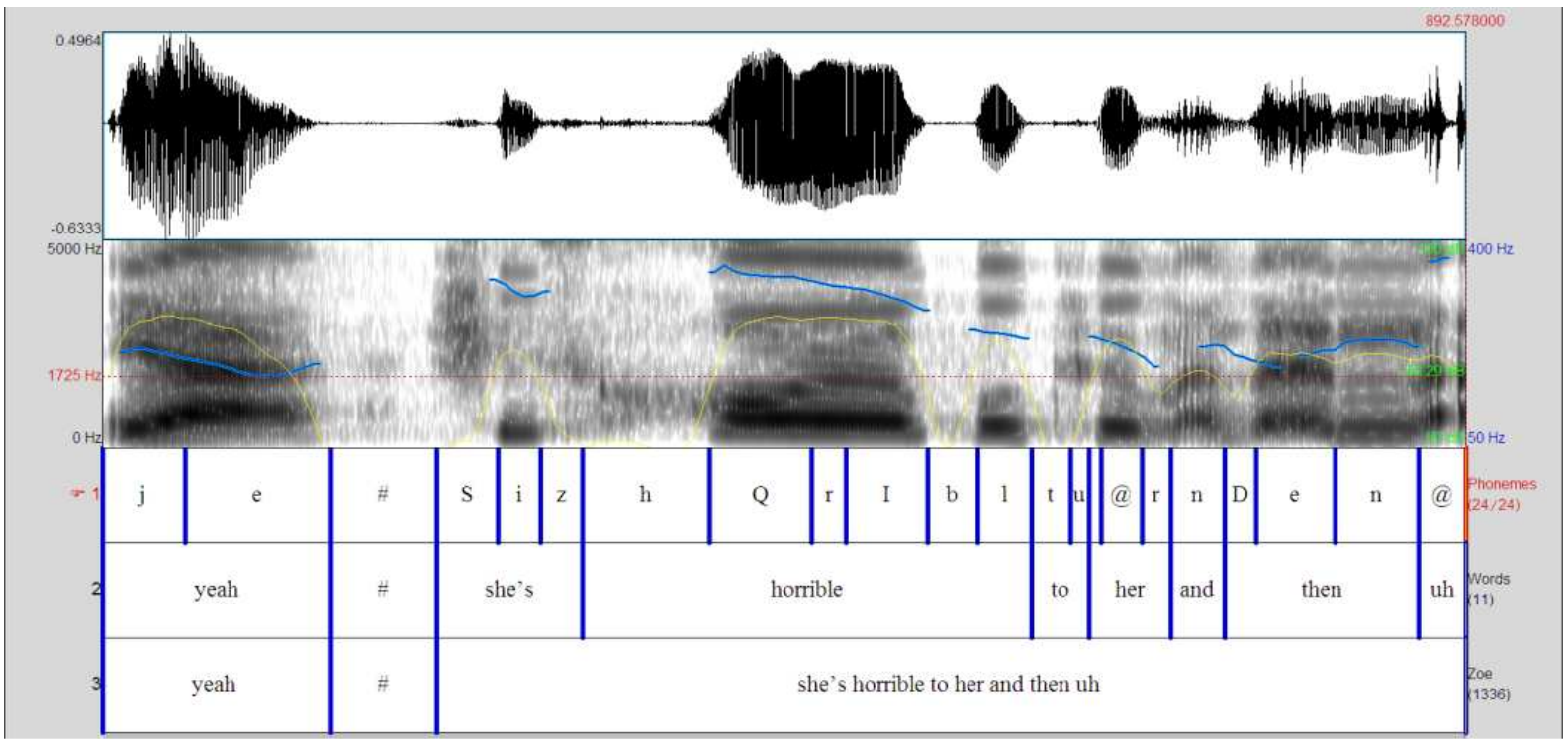

Figure 2. Praat window showing the waveform (top), the spectrogram together with the pitch track in blue and intensity curve in yellow (middle part), and utterance transcription in phonemes, words and Intonation Phrases (bottom part) of "yeah \# she's horrible to her and then uh"

Example (26) was uttered by a participant who is describing a party she went to where there was a kind of music she liked which she illustrates talking about the hair style of the guests ('people with dreadlocks'). Whereas the beginning of the hyperbole 'I was in heaven' does not show any prosodic emphasis, all the emphasis is carried by 'loads' which carries the largest intensity peak of the utterance and shows a large rise-fall contour in pitch and which is also is lengthened being 1.5 times longer than the sum of the mean duration of its separate sounds in the rest of the conversation for this speaker (see Figure 3). Claridge (2010: 50) mentions that the long vowel sound in 'loads' is "phonetically iconic in contrast to 'lots" which has a short vowel sound, so the extra lengthening of 'loads' in this example adds to the emphasis. 
(26) I was, I was in heaven, I(h) was(hh) huh huh. (0.4) There was loa:ds (of) people with dreadlocks.

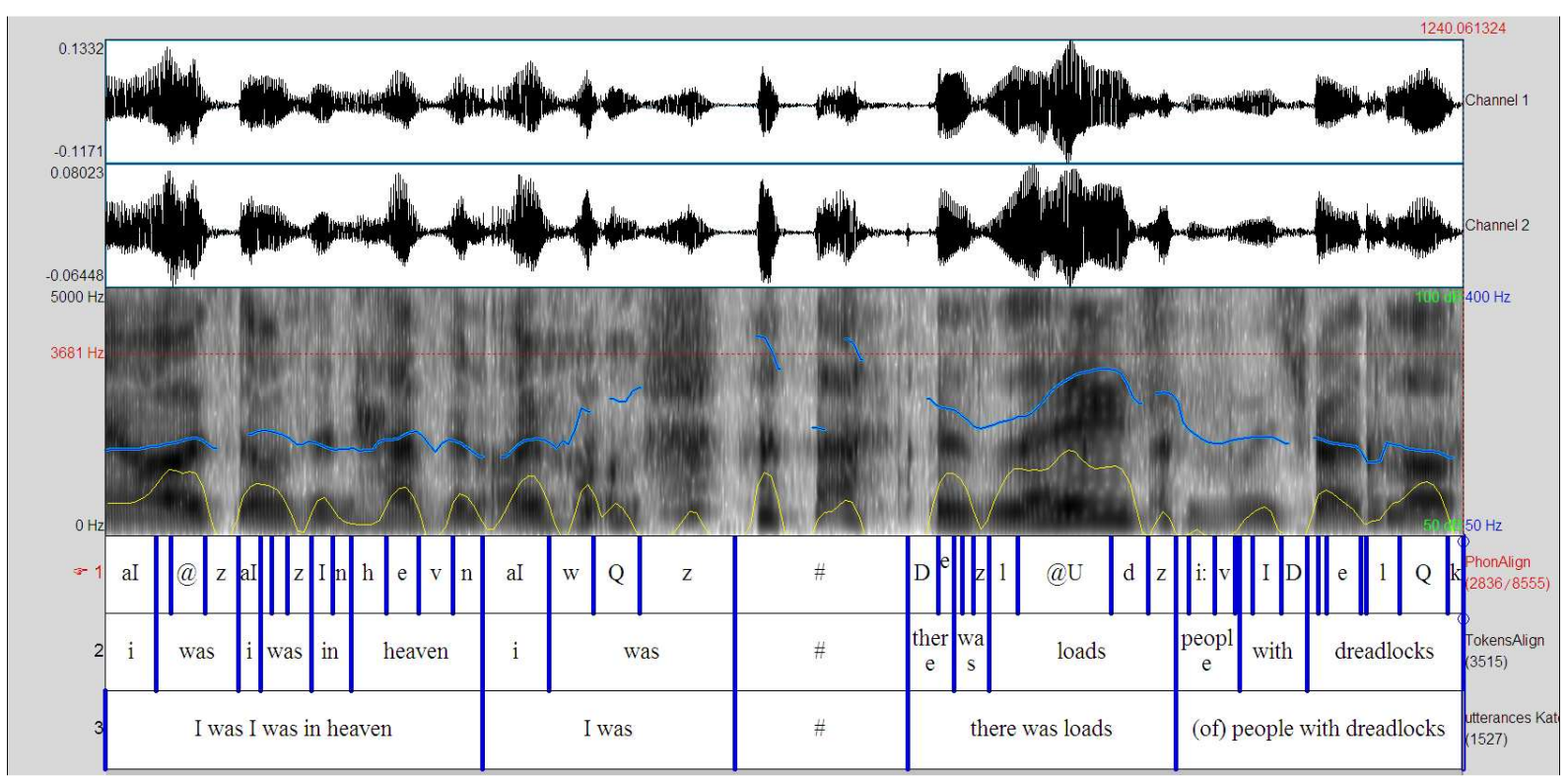

Figure 3. Praat window showing the waveform (top), the spectrogram together with the pitch track in blue and intensity curve in yellow (middle part), and utterance transcription in phonemes, words and Intonation Phrases (bottom part) of "I was I was in heaven I was \# there was loads (of) people with dreadlocks"

\subsection{Prosodic enactments}

Apart from being emphatic on hyperbole, prosody can serve verbal hyperbole itself or even be hyperbolic as will be shown in the three examples below. In example (27), Kate and Beth are discussing shopping for food. Kate makes an overstatement when she says that the mixed beans she wants to buy are only sold in a shop called Morrison's. This statement provokes Beth's laughter, which is why she comes up with 'I'm not joking.' What is however particularly interesting from a prosodic viewpoint, as shown in

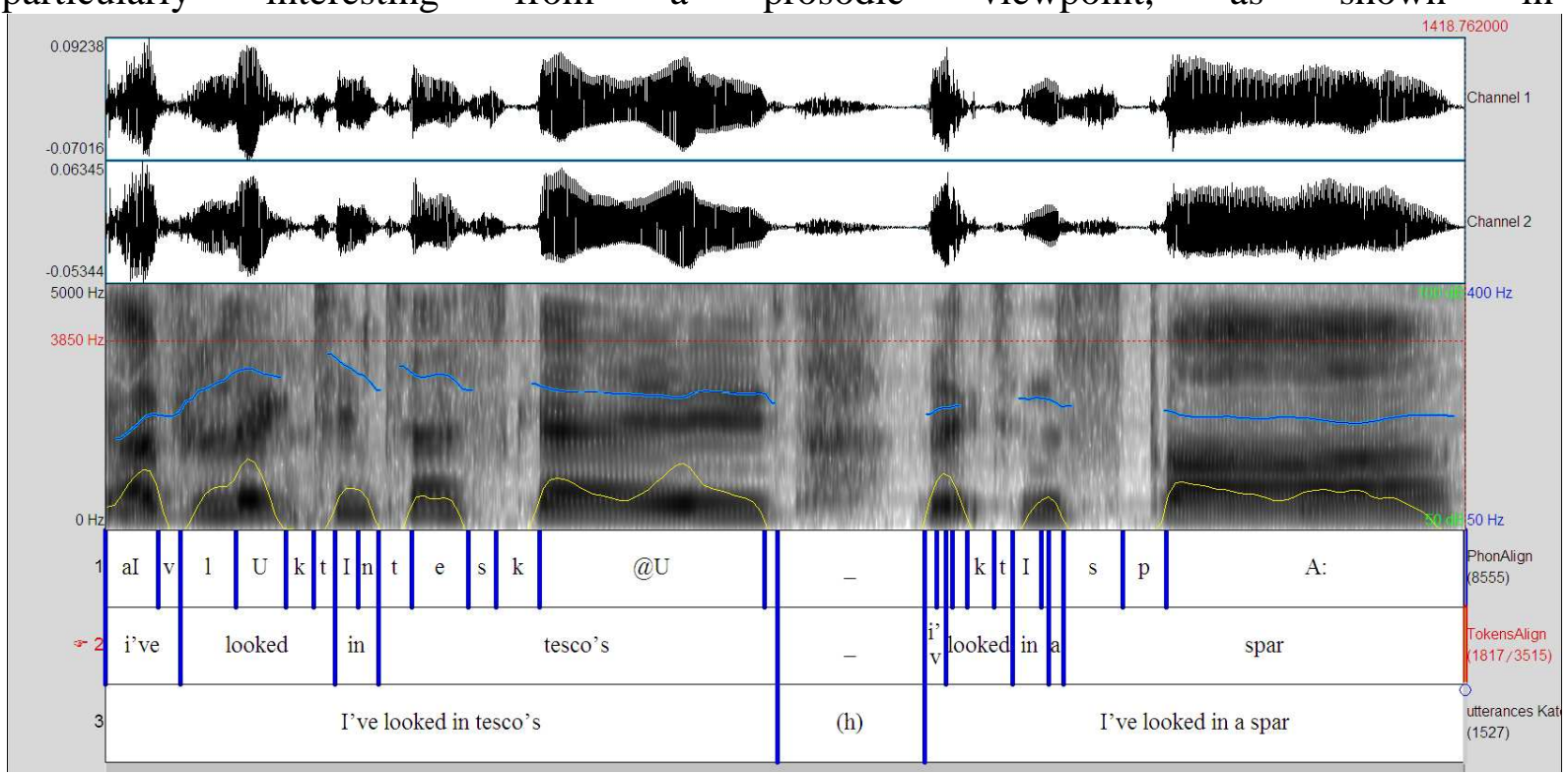

Figure 4, is that she illustrates her hyperbole starting a list of all the other shops which do not 
have the mixed beans. In 'I've looked in Tesco's', the last vowel is lengthened by 2.8 times, and the vowel in 'Spar' is also lengthened by 4.2 times in 'I've looked in a Spar'. Both syllables show a flat intonation contour in medium pitch and the conjunction of the two features are the typical contours of lists. Yet, in a closed list, the last item is not lengthened and has a falling contour in a statement. The fact that Kate maintains a flat contour on 'Spar' means the list is open and could be extended to all the other shops in town. She immediately self-corrects with 'those are the only two places I've looked' but maintains the initial hyperbole in her last turn ('no, they only sell them in there').
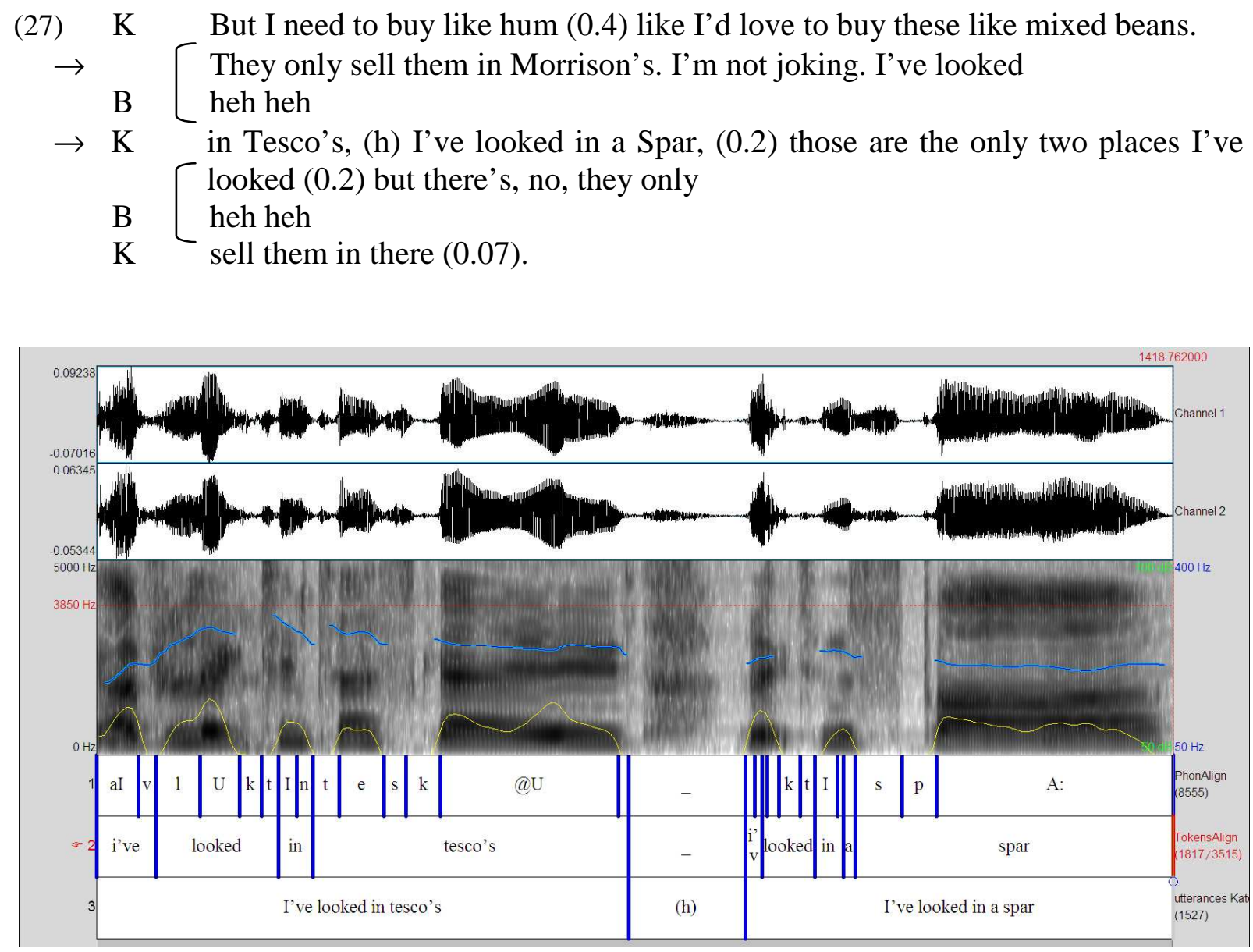

Figure 4. Praat window showing the waveform (top), the spectrogram together with the pitch track in blue and intensity curve in yellow (middle part), and utterance transcription in phonemes, words and Intonation Phrases (bottom part) of "I've looked in Tesco's (h) I've looked in a Spar"

Even in the presence of the self-correction, we can say that prosody in these two Intonation Phrases conveys some hyperbolic meaning which was already present in Kate's first turn at speech. In Example (28) below, Zoe and Michelle are speaking of their accent when they teach English as a Foreign Language in France:

(28) $\mathrm{Z} \quad$ And then hem yeah (0.1) and then I think when you're speaki:ng (0.9) your language, you're teaching your language, then you te:nd to change your accent. $(0.2)$

$\begin{array}{ll} & \text { M } \\ \text { Z } & \text { Yeah, I do.= } \\ & \text { M } \\ \rightarrow & \text { Hehehe. }=\end{array}$ 


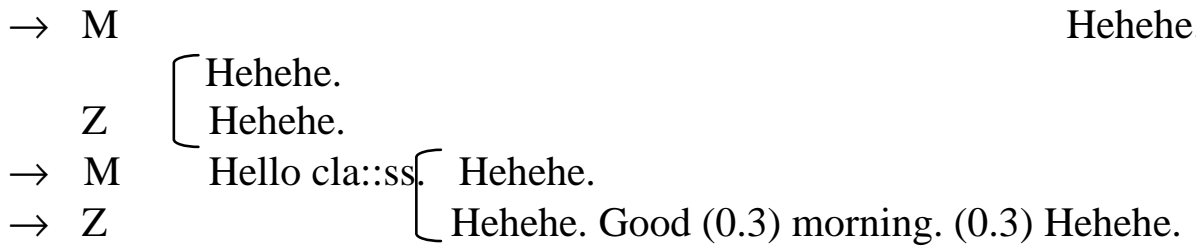

Zoe proposes the hyperbole saying that she has to speak 'twenty times slower than usual', which is immediately taken up by Michelle in the following turn when she says 'teacher speak' at a very slow speech rate (with a lengthening of the last vowel by 2.2 times), a process which she repeats later with 'hello class' (with a lengthening of the last vowel by 3.6 times). Zoe also continues the hyperbole with 'good (0.3) morning'. This time, although the length of each syllable is fairly normal, there is a silent pause in between the two words which slows down the speech rate of the Intonation Phrase. Once again then, we can say that prosody is hyperbolic in this example and serves the hyperbole that was stated verbally.

Example (29) below is a bit more complex. The same participants as above are having an argument on a film that was shown on television not long before the recording of the corpus. Michelle did not like the film for two reasons: the main character had a horrible voice, and the part of the film Michelle watched was very banal, to which Zoe counter-argues that this is because the scene is improvised and that the film is good overall. For clarity, passages which resort to prosodic enactments are underlined and verbal hyperboles are numbered (a), (b) and (c).

(29) M But I put it on in the bit where hem (0.3) (h) they: (h) they we:re uh (0.9) in the garden, and they were talking, (0.3) and it was really really banal, everything that was going on (0.1). Ooh, wou:ld you like another (0.2). Would you like

$\mathrm{Z}$
$\mathrm{M}$
$\mathrm{Z}$$\quad\left[\begin{array}{ll}\text { another } & \text { bi:scuit. } \\ \text { Yeah. } & \text { Would you like another cup of }\end{array}\left[\frac{\mathrm{tea}}{\mathrm{No}}\right.\right.$

No, but that's Mike Leigh all over because, that's the kind of he: (0.5), everything's meant (0.1), quite a lot of his films are improvised. (0.2) Like a lot of the scenes That scene was improvised. Yeah, cos I got the impression they weren't (0.5) some of $(0.2)$

$\mathrm{Z} \quad$ No, that scene is im provised.

(a) $\mathrm{M}$

doing it, I: mean. You couldn't write a script like that, you'd fall a:sleep

$\mathrm{Z} \quad$ No no no, cos it's meant to be, $(0.2) \mathrm{m}$ - most of the scenes are very banal everyday li:fe. (0.1)

M Mhmh (0.3).

$\mathrm{Z} \quad$ And hem that's why he gets people to improvise. And he gets (0.2). It's a real-

(b) M Ah, she had such a ho:rrid voi:ce. (h) She sounded like a ban:shee.=

$\mathrm{Z}$ Hehehe.=

M Would you like another biscuit. (0.1) And then I was just thinking, oh my (0.2) god, this is so bo:ring. (h) (0.4) And then, (1.1) what happened, (0.6) that's me daughter. (0.2)

$\mathrm{Z}$ Hehehe. $=$

(c) M Gnagnagna::. And the whole film was (0.5) wa:s a: complete explosio:n.

Z I: kno:w. 


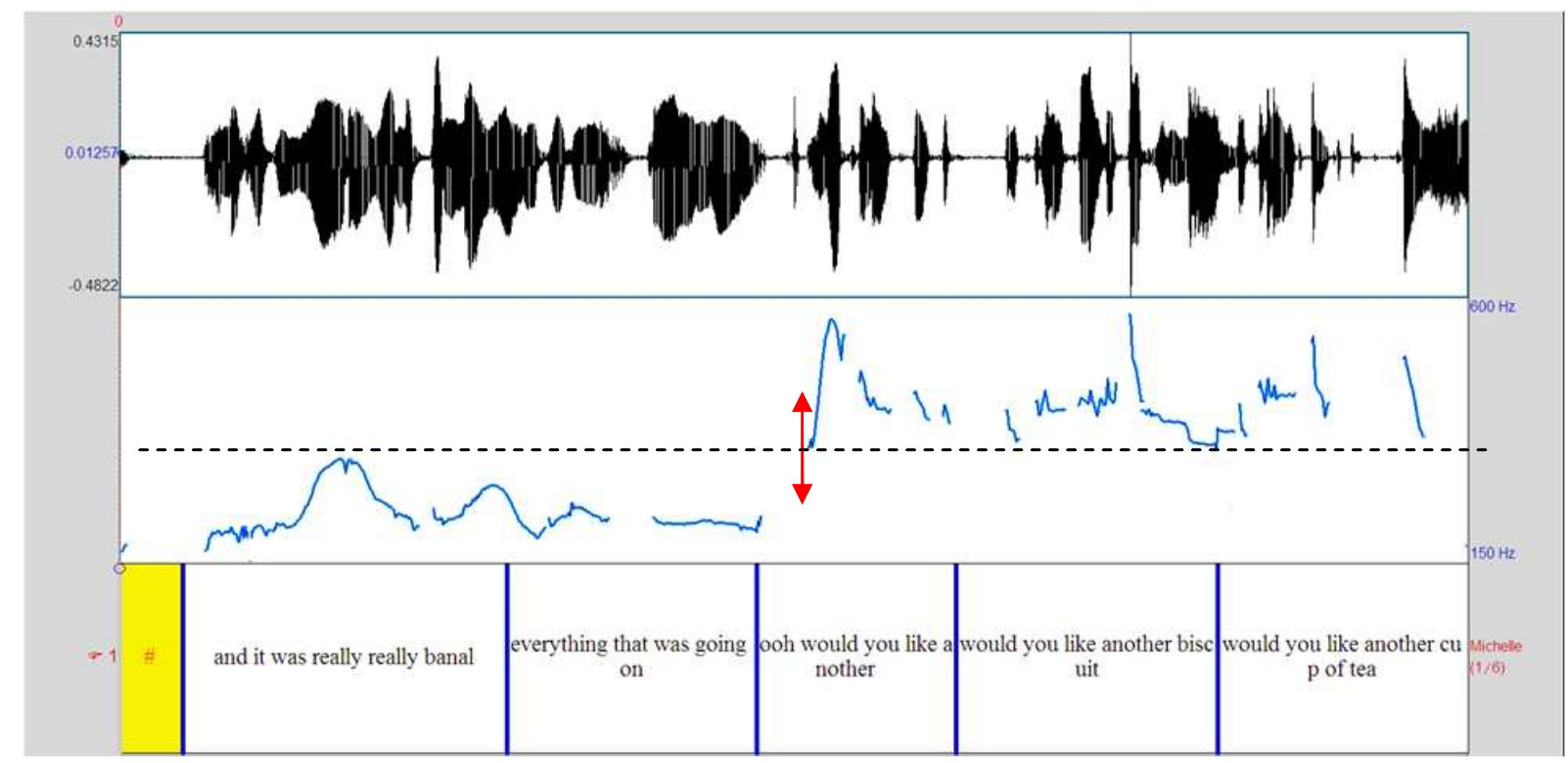

Figure 5. Praat pitch curve of / and it was really really banal / everything that was going on / ooh would you like another / would you like another biscuit / would you like another cup of tea /

In her first turn, Michelle starts with what is probably a slight overstatement 'it was really really banal, everything that was going on', emphasized by the dislocated syntactic construction, but at this point, the hyperbolic intention is not fully stated. She however illustrates this with 'ooh, would you like another, would you like another biscuit, would you like another cup of tea' which makes the scene sound indeed ordinary. What is interesting though is the radical change in pitch key on this particular part of speech, which is shown in Figure 5: whereas the first two Intonation Phrases are uttered at a mean pitch of $210 \mathrm{~Hz}$, Michelle's pitch jumps up to $470 \mathrm{~Hz}$ on the reported speech. This means that there is a difference of more than an octave in between the framing discourse and the reported speech. And all the instances of reported speech that occur later in the passage are also uttered at a very high pitch. What is interesting though is that in the first turn, the hyperbole on the character's voice has not yet been verbalized so that the reported speech at this point in the passage serves the hyperbole on the fact that the film was boring (the real hyperbole comes later though: (a) 'you couldn't write a script like that, you'd fall asleep doing it, I mean' and (c) 'the whole film was a complete explosion') as well as it serves hyperbole (b): 'she had such a horrid voice, she sounded like a banshee', and we see that both verbal hyperboles and hyperbolic prosody are intertwined in Michelle's argument. The prosodic enactment of the high-pitched voice of the character in the film is caricatural and constitutes hyperbolic speech not so much in verbal content but rather in speech form.

\section{Gestural properties of hyperbole 5.1. Focalization gestures}

Ferré (2003, 2004) confirmed Birdwhistell's observation (1970) that a typical gesture linked to focalization in English is eyebrow raising, an observation made on other languages as well (Krahmer et al., 2002; Krahmer \& Swerts, 2007; Swerts \& Krahmer, 2008, among others). Eyebrow raising very frequently accompanies intensifiers in ECFs, but it is also very much present in cases of hyperbolic speech. Eyebrow raise can be realised as either a flash of the brow or it can be sustained throughout an entire Intonation Phrase. Example (15) is reproduced below: 
(30) David had always waited for me at the station, so to arrive at the station and suddenly have no one waiting for me, that would have been the worst thing in the world.

In the example, Zoe is telling Michelle how difficult it was the last time she came back to France, especially since her boyfriend wasn't there, and one can see that she raises her brows regularly in the passage, on both intensifiers 'always' and 'suddenly', but also on 'arrive' and 'station'. What is relevant in the passage though is that 'worst' being the superlative form of 'bad', it is felt as more extreme than 'always' on their respective gradation scales, and it is precisely on 'worst' that the speaker overloads her speech from a gestural viewpoint since she raises her brows twice in quick succession on this particular word.

In (31), the two participants are talking of the shop 'Littlewoods', which they apparently both dislike, because of the fact that it is 'expensive' according to Zoe, but also because they dislike the clothes. Notwithstanding the fact that Michelle's second turn is highly unexpected when one considers her prior turn in which she uses the verb 'drag' in the hyperbole (this verb projects a negative appreciation of the shop and thus makes the next positive comments unexpected), the speaker flashes her eyebrows on 'jumpers', thus showing that there is a disjunction (the eyebrow flash seems to tell that the jumpers are so nice it is hardly believable). Not only the words but also the gestures here serve to show the irony in this particular utterance. The reported speech that follows shows prosodic iconicity with 'hurry up' and 'mum' being uttered at a fast speech rate.

(31) M My mother always drags me to Littlewoods huhuhh.=

$\mathrm{Z} \quad$ I never go. It's really expensive as well. (0.3)

M I kno:w. (0.5) And you get these nice patterned jumpers, (0.1) and uh (1.4) nice A-lines skirts, (0.5) remember going, mu:m, (0.1) hurry u:p (0.1) huhuh. Hurry up, mum. I'm going in Dorothy Perkins.

At last, in example (32) below, Michelle is talking about the staff facilities of a shop she used to work in, e.g. that they could buy food that was just past its sell-by date at a cheaper price. She flashes her eyebrows quickly on the two contrasted prices (the original price and the price she bought the strawberries at), and then raises her brows during almost the entire clause 'we cleared the shelves out' that carries the hyperbole. She then produces a quick flash of the brow on 'five' which is also uttered with emphatic stress. We will come back to this example later as there is more to it than just eyebrow raising in terms of the gestures made by Michelle.

(32) One year, they had these huge punnets of strawberries, and they were, no joke, about that big. (0.7) And they were three ninety nine. (0.3) Amazing huge strawberries. (0.2) And we got them for twenty pence a punnet. (0.5) So I went into the shop, and we cleared the shelves out. Huhuhhh. I took about five punnets of strawberries.

\subsection{Gestures that contribute to verbal hyperbole}

Some other gesture types cannot be qualified as hyperbolic since they are very small and do not convey any hyperbolic meaning in themselves, but nevertheless participate in the expression of verbal hyperbole. In example (33) below, Tim and Tom are discussing the driving test they passed a few years before the recording, and Tom is saying that it took him some time after the driving lessons to feel confident on the road. The argument is that one 
needs quite a lot of driving experience to become a good driver. He illustrates his point with the example of his girlfriend who stopped driving for some years in between the driving test and the time when she could actually drive:

(33) Tom You've, I've noticed that with (0.3) hem Hannah, (0.2) my friend, (0.1) you know, Hannah? (0.3)

Tim Oh yeah.=

Tom $[$ She's just got her car and she (0.1) passed the test a few years ago.

Tim Yeah.

Tom Hasn't driven since. $=$

Tim Oh okay.=

$\rightarrow$ Tom And now you get in the car with her she's a bit like (1. JOLTS)

Tim Right huhuh.

$\rightarrow$ Tom And we're hopping everywhere, and now, and you can tell like (0.21) when people are new to driving.

(a)

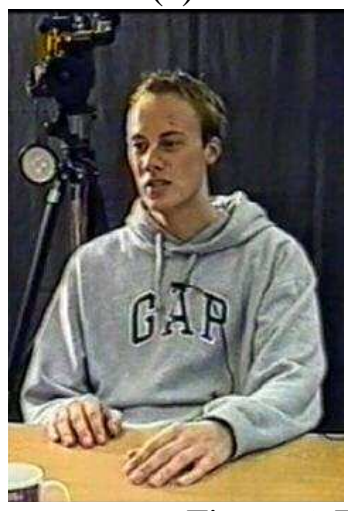

(b)

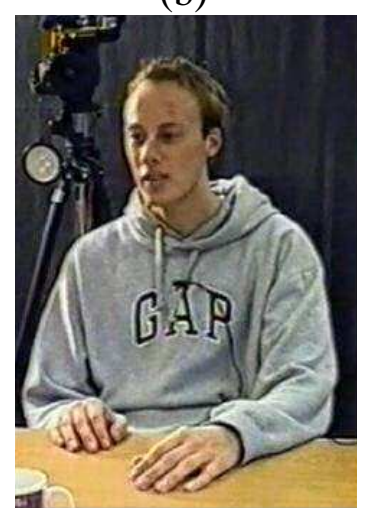

(c)

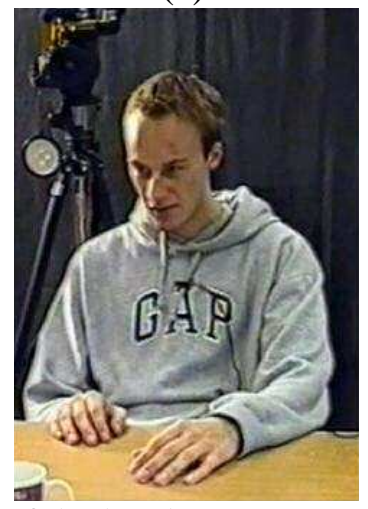

Figure 6. Tom producing a slight jolt of the head

The verbal hyperbole in this passage is 'we're hopping everywhere' (due to the jerky and somewhat abrupt movements of the driver instead of the required smoothness). Just before the verbalization of the hyperbole, Tom produces a slight jolt of the head, shown in Figure 6 . His head moves slightly forward and then down and back to rest position. The gesture mimics the movements made by car passengers as the car bounces due to the jerky movements of the driver. Because the gesture is small, it does not at this point convey any hyperbolic meaning, but it supports the immediately following verbal hyperbole in enabling the co-participant in the interaction to visualize the consequences of the driver's actions.

Later in the interaction, Tom is describing a car accident he had on the motorway:

(34) Tom And I think someone must have gone down the slip road and have crossed two lanes, (0.2) and caused everyone to brake (h广 and

Tim $\mathrm{mh}$

Tom the car in front of me was a nice big Mercedes with (0.3) brake assisting and Tim $\left[\begin{array}{l}\text { stuff, and } \\ \text { Yeah. }\end{array}\right.$

$\rightarrow$ Tom they stopped (SNAPS FINGERS) like $\left[\begin{array}{l}\text { that, } \\ \text { Tim no. }\end{array}\right.$
Th

$\rightarrow$ Tom and my little Peugeot 106 went (IMITATES THE SOUND OF A CAR BRAKING IN EMERGENCY) $=$ 
Tim No:: huhuhh.

Tom skidding on on the wet road, bang, into the back of it and then a Fiesta in the back of me.

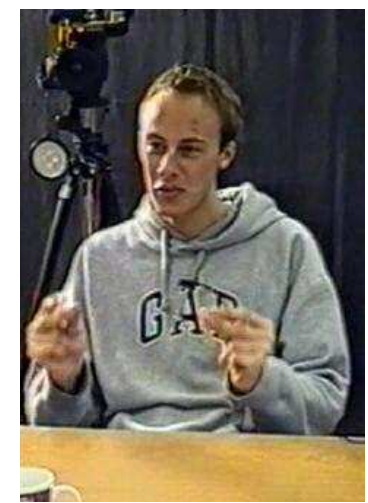

Figure 7. Tom snapping his fingers in the utterance 'they stopped (SNAPS FINGERS) like that'

The hyperbole in example (34) is neither verbal nor gestural. What makes the statement 'so they stopped like that' hyperbolic is the combination of gesture and speech. Finger snapping is not hyperbolic in itself: the hyperbolic effect depends much on the context of production. In many contexts though, the emblematic gesture has become a conventionalized way of meaning 'in an instant' or 'in a second', which is the meaning it takes in this example. What can be noted here though is that the gesture takes a semi-conventional value insofar as it is a double-handed instead of a single-handed gesture (a gestural reinforcement device very much akin to the syntactic polysyndeton described in Section 1.3). In the context of a car driving on the motorway, it becomes hyperbolic. The onomatopoeia that follows in the next turn (/kr:::/ as an approximation of the sound mimicking car braking) affords a contrast with the immediate and silent braking of the 'nice big Mercedes' and therefore also contributes to the hyperbole.

\subsection{Hyperbolic gestures}

Whereas the gestures mentioned above are not hyperbolic themselves but still contribute to the hyperbole, other gestures are clearly hyperbolic in their form, either because they are large gestural enactments and/or because some of their features convey a hyperbolic meaning. Let's have a look again at the gestures produced in a previous example:

(35) One year, they had these huge punnets of strawberries, and they were, no joke, about that big. (0.7) And they were three ninety nine. (0.3) Amazing huge strawberries. (0.2) And we got them for twenty pence a punnet. (0.5) So I went into the shop, and we cleared the shelves out. Huhuhhh. I took about five punnets of strawberries.

(a)

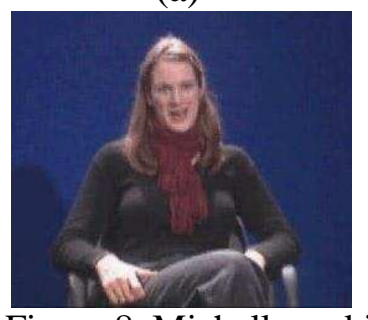

(b)
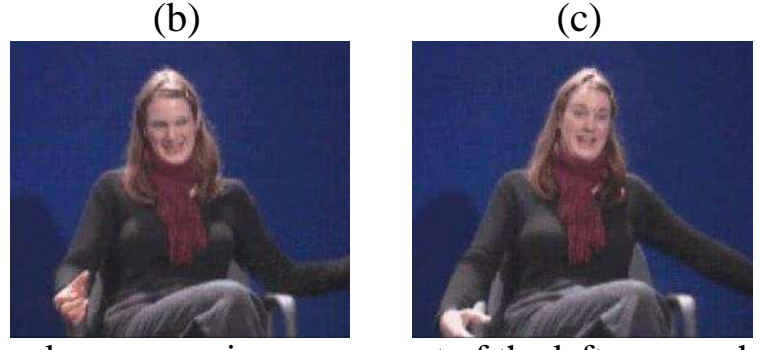

(d)

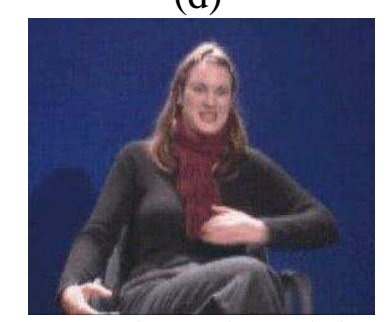

shelves out' 
Figure 8 reproduces Michelle's large sweeping movement of the arm (a characterviewpoint ${ }^{3}$ iconic, C-VPT) as she utters the hyperbole 'and we cleared the shelves out'. Leaving her lap, Michelle's left hand moves towards the extreme lower left periphery of her gesture space (McNeill, 1992: 89). Her arm then bends towards her body. The gesture is hyperbolic in two respects: first because of its size (it is Michelle's largest gesture in the recording and the only time when her hand comes off-camera as shown in Figures 8a and b), and second because of its shape. With such a movement of the forearm, the flat palm of the hand oriented towards her body, Michelle's gesture is not one that illustrates the expected 'taking' of the individual punnets, but is rather an illustration of the collection at the same time of all the punnets on the shelf.
(36) M I know, I could see people getting sort of (0.8 TUGS AT SCARF)
$\mathrm{Z} \quad$ Huhuh a little bit stressed.=
M Kids running up and down the carriage and people getting sort of white knuckles, gripping the (0.8) sides of their seats. (0.2)
$\mathrm{Z} \quad$ But it's such a long=
M Somebody keep those kids under control.

In example (36), Michelle is telling Zoe about the time when the train got stuck in the Channel Tunnel ${ }^{4}$ and while doing so, makes two character-viewpoint iconic gestures: first, as shown in Figure 9 (a) and (b), she tugs at her scarf several times, thus mimicking people feeling ill at ease and this is interpreted as such by the listener who comes in here to express verbally what was only expressed in the gesture made by her friend 'a little bit stressed'. The gesture is clearly caricatural and hyperbolic whereas nothing expresses hyperbole in Michelle's speech. Then comes a second iconic gesture shown in Figure 9 (c), the speaker grips firmly the armrests of her chair, this time mimicking what is expressed verbally as 'gripping the sides of their seats'. The phrase 'white knuckles' is interesting as well since it is represented in the gesture by the fact that she grips her seat arms firmly. This time, then, both the gesture and the speech are hyperbolic.

(a)

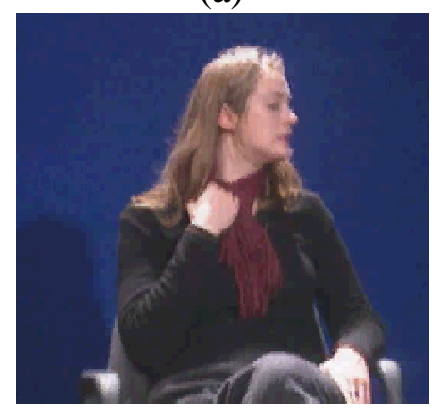

(b)

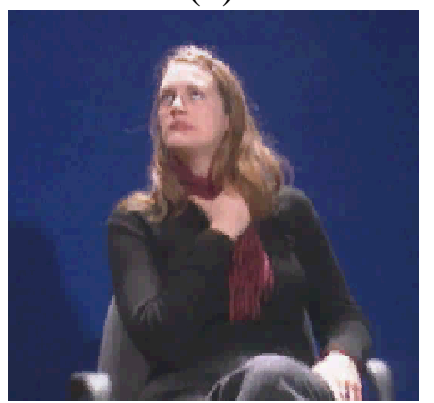

(c)

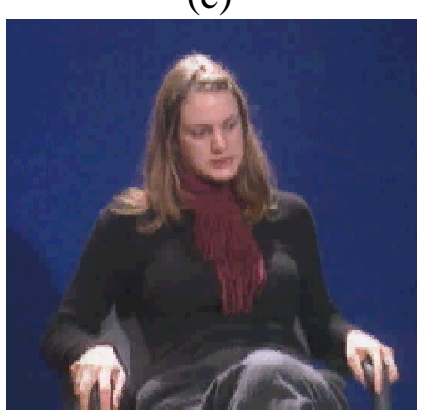

Figure 9. Michelle mimics people getting stressed under the Channel Tunnel with two characterviewpoint iconics

In example (37), Kate is telling Beth how to properly eat king prawns, according to her father.

\footnotetext{
${ }^{3}$ McNeill (2005) distinguishes observer-viewpoint iconics (representational gestures in which the speaker's hand(s) represent(s) the whole character) from character-viewpoint iconics (representational gestures in which the character is represented the whole body of the speaker).

${ }^{4}$ The Channel Tunnel is a $50 \mathrm{~km}$ long tunnel linking France and England.
} 
B Cohuh.

$\mathrm{K}$ Cos I really didn't know how to do it and I just went to eat it and he was like

$\rightarrow \quad$ B $\quad\left[\begin{array}{l}\text { no::. (1.0) So like he } \\ \text { Huhuh. }\end{array}\right.$

$\rightarrow \mathrm{K} \quad$ yanked the heads $\left[\begin{array}{l}\text { off, } \\ \text { Yeah. }\end{array}\right.$

$\rightarrow \mathrm{K} \quad$ and then pull the (0.1) pull the skin off the (0.5). Do you not like it? (0.2)

As she produces the verbal hyperbole 'so like he yanked the heads off', in which the verb 'yank' is a little bit strong when applied to king prawns, Kate also makes a large iconic gesture. This is shown in Figure 10 below on the images numbered (a) to (e). (a) shows the position of Kate's hands as she utters 'no' and during the subsequent pause. When uttering 'so like he', her right hand moves to the left in a large circular movement shown in (b) and (c) at which point her fist closes as if to grab the prawn's head. From (c) to (e), as Kate is uttering 'yanked the heads off', her hand makes a rapid movement back to the right. The gesture looks hyperbolic both in its size which is large when considering the size of prawns (a smaller gesture would have been perfectly adapted to the action described), and in its velocity. You don't really need to pull off the animal's head quickly. The gesture looks large as well because of the fact that Kate makes few hand gestures in the conversation, most of them being small or medium sized, so that this one stands out as particularly prominent. As Kate utters 'then pull the $(0.1)$ pull the skin off the', she makes a very similar gesture to the first iconic produced in the passage, yet slower than and not as large as the first one. The gesture can still be considered as hyperbolic as compared with the size of prawns.
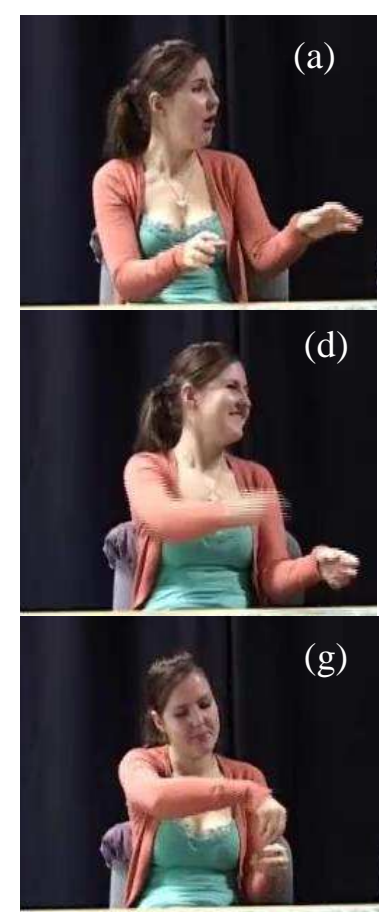
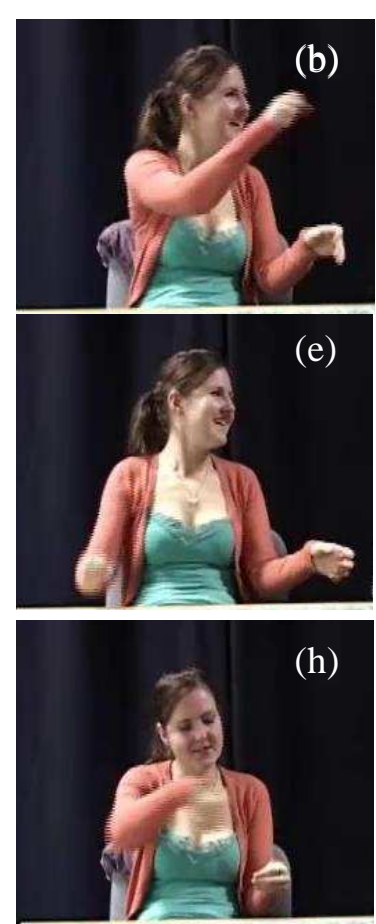
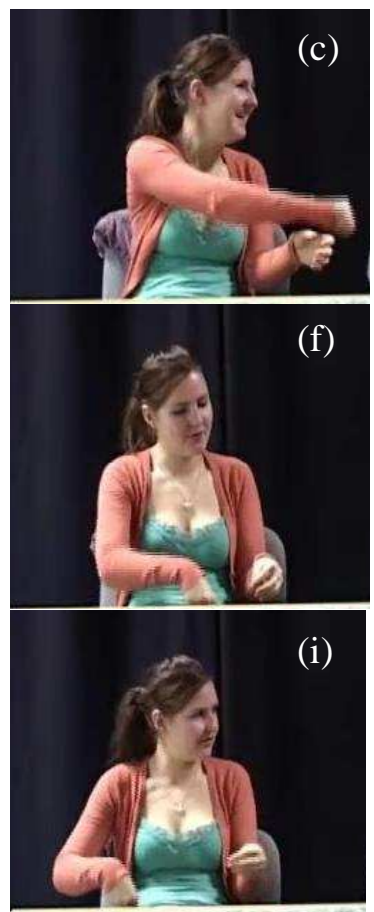
Figure 10. Kate produces two hyperbolic character-viewpoint iconic gestures (Gesture 1 from (a) to (e) and Gesture 2 from (f) to (i))

At last, in (38) below, Michelle and Zoe again are talking of their experience as language assistants in French schools. At this point of the interaction, Michelle is talking of a particular boarding school, a former convent, she worked at and which looked eerie during weekends when the pupils and teachers had gone home.

(38) M Yeah, (1.5) yeah. And that was, that was really strange in the holidays, because sometimes, (h) when everybody went home, I'd stay for a weekend, and (1.3) anyway, anyone, (0.08) everyone went home weekends, but I'd stay sometimes, (h) (0.7) and uh (h) (0.1) it was an old convent as well, (0.2)

$\mathrm{Z}\left[\begin{array}{l}\text { so it was really creepy, } \\ \text { Mhmh }\end{array}\right.$

M especially in winter, when it got really dark.

$\mathrm{Z} \quad$ Yeah all the creeks of the wind, and yeah, that's horrible. (0.4)

$\rightarrow \quad \mathrm{M} \quad$ I'd go down to use the hem public telephone, and I have to go sort of weave my way through these like arches and pillars.

She produces a verbal contextual hyperbole in her first turn which might go unnoticed: she states that she used to stay alone in the school then, which is obviously untrue. There must have been the other language assistants (she has just said that there were several assistants in the school), a caretaker and we know that in most boarding schools, the headmaster and family often live on the premises as well. So, although the school certainly looked deserted, the statements 'when everybody went home' and 'everyone went home weekends' are most certainly overstatements. Yet, the real hyperbole comes later in the passage with the metaphor 'and I have to go sort of weave my way through these like arches and pillars'. This is a semiconventional hyperbole insofar as it is a set-phrase but used in a context which is quite unusual: in old convents, you generally walk straight in alleys and don't have to slalom in between pillars. The hand gesture that accompanies the metaphor directly matches the speech with repeated movements of the hand towards the left and the right but also with the shape of the hand (particularly visible on image (b) of Figure 11): the index and little fingers are extended figuring the shape of the shuttle used in weaving cloth. The gesture thus has two dimensions: an observer-viewpoint iconic (O-VPT) dimension of slaloming and a metaphoric dimension of weaving, and contributes fully to the verbal hyperbole.

(a)

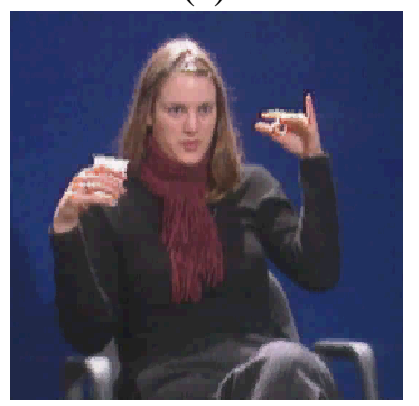

(b)

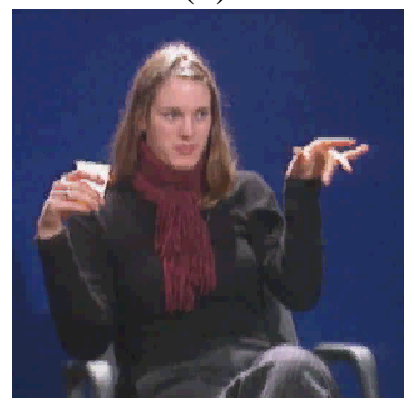

(c)

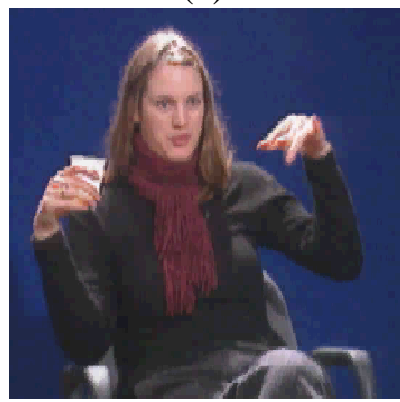

Figure 11. Michelle's hyperbolic hand gesture on the metaphor 'weave my way'

\section{On the communicative dynamism of hyperbole}


In the previous sections of this paper, we have seen that hyperbole may be expressed verbally, but that there is also a strong tendency for hyperbolic speech to be reinforced by marked prosodic patterns (sound lengthening, sound repetition, high pitch and intensity) and gestural features (two-handedness, large gesture size, greater articulatory tension), thus confirming McNeill's idea that 'speech and gesture respond in the same direction' (2012: 127), as they are part of a single communication system. Since hyperbole consists in the enhancement of certain verbal content (towards positive or negative values), it brings with it an exceptional degree of materialization under the form of caricatural prosody and gestures. McNeill (op. cit., p. 126) notes that gestures are more present and made more visible (two-handed gestures, for instance) when the psychological predicate is more newsworthy. The same could be said of marked prosodic patterns. Now, newsworthiness of an experience is precisely the type of marking made by hyperbole, so it is natural that we find marked prosody and emphasized gestures with it. That these material carriers may express hyperbole without any enhancement in speech can be considered as a larger materialization of a direct experience, an experience not mediated through speech.

In 2005 and 2012, McNeill showed how the use of particular linguistic and gesture forms is linked to the degree of communicative dynamism, defined as "the extent to which a given spoken or gesture form "pushes the communication forward" (2012: 126). Since the role of hyperbole is to make an event newsworthy as explained in the previous paragraph, it may be considered as involving a high degree of communicative dynamism. Yet, in view of the different schemata presented in this paper as well as considering the definition of hyperbole presented in section 1.1, hyperbolic speech is also gradable in terms of communicative dynamism. Table 1 below, inspired from McNeill's analysis of communicative dynamism in unmarked linguistic forms (2012: 127), presents a grading of the degrees of communicative dynamism involved in the different forms of hyperbole.

\begin{tabular}{|c|c|c|c|c|}
\hline & \multicolumn{4}{|c|}{ Most Continuous/Predictable } \\
\hline & Less Materializatior & & $\longrightarrow$ & Iore Materialization \\
\hline 岕. & \multicolumn{4}{|c|}{ Linguistic Form Continuum } \\
\hline . & $\begin{array}{l}\text { Contextual } \\
\text { hyperbole }\end{array}$ & $\begin{array}{c}\text { Conventional } \\
\text { hyperbole }\end{array}$ & $\begin{array}{c}\text { Semi-conventional } \\
\text { hyperbole }\end{array}$ & Creative hyperbole \\
\hline & \multicolumn{4}{|c|}{ Prosodic Form Continuum } \\
\hline$\downarrow$ & Emphatic stresses & Sound repetition & Sound lengthening & $\begin{array}{l}\text { Higher pitch \& } \\
\text { intensity \& sound } \\
\text { lengthening }\end{array}$ \\
\hline$\frac{\mathbb{N}}{\pi}$ & \multicolumn{4}{|c|}{ Gesture Form Continuum } \\
\hline$\sum_{\Sigma}^{0} \sum^{\frac{0}{\sigma}}$ & Eyebrow raises & Emblems & $\begin{array}{l}\text { Metaphorics } \\
\text { O-VPT iconics }\end{array}$ & large C-VPT iconics \\
\hline
\end{tabular}

Table 1. Communicative Dynamism of hyperbole (based on McNeill, 2012: 127)

Table 1 presents a two-dimensional scale of the continuum of Communicative Dynamism of hyperbole. On the vertical axis, the linguistic form being more predictable to communicate exaggeration, this material carrier represents less materialization. On the contrary, more body movements are less predictable and show more discontinuity, and are therefore heavier 
material carriers. Marked prosody features lie in between linguistic forms and gestures, since prosody is the result of a complex gesture involving the vocal organs, but the original gesture(s) that produce(s) a prosodic pattern is not directly visible by the listener most of the time (tension of the vocal cords, for instance, can only be inferred from the resulting pitch, whereas long closure of the lips in a bilabial consonant resulting in sound lengthening is directly accessible by the addressee). Of course, we should add that hyperbolic speech produced with marked prosody and accompanied with a gesture conveys even more materialization than some hyperbole expressed only in the form of gesture.

The horizontal axis presents the different forms of hyperbole in the linguistic mode first. The contextual hyperboles (use of an unexpected verb form in context or mismatch of a sentence with situation) are the least 'creative' and therefore the most predictable forms of exaggeration. They are also the most frequent ones. Then, the scale established by Claridge (2010), going from conventional to creative hyperboles, corresponds to the grading of materialization, simply because creative hyperboles require more cognitive effort on the part of the speaker and listener, and being less expected, they show a greater shift in footing and more discontinuity with previous discourse.

The prosodic carriers are in direct correspondence with the linguistic material, which means that the most frequent pattern with a contextual hyperbole is the simple marking of a syllable with emphatic stress. Emphatic stress is used quite frequently in conversations and is not dedicated to exaggeration (which is why it is considered as the most predictable carrier), but when combined with contextual hyperbole, it enhances it. We have also seen that conventional hyperbole very frequently relies on sound repetition (as in fuddy $d u d d y$ ), whereas a semi-conventional type would rather involve sound lengthening (especially an extension of the vowels, contrary to emphatic stress which involves an extension of the syllable onset only). At last, creative hyperboles will rather appeal to a combination of prosodic features: higher pitch and intensity as well as sound lengthening. This combination is to be understood as an exaggerated form of emphatic stress and clearly requires more effort on the part of the speaker for its production. Being rare in conversational data, it is also less expected.

At last, hyperbole can also be graded in terms of the gestural carriers of the message. We have seen that one of the correlates of emphatic stress is eyebrow raising, whereas emblems are more likely to accompany conventional hyperbole if any gesture is to be produced together with speech. Emblems being conventional gestures, they can also be used on their own and still convey hyperbolic meaning in particular contexts (finger snap expressing instantaneity for instance), which is not the case of eyebrow raises. More gestural creativity is found with semi-conventional hyperboles and if a hand gesture accompanies one, it is more likely to be in the form of a metaphoric or an O-VPT iconic, the latter showing less embodiment on the part of speakers than when they make a C-VPT iconic (the type preferred with creative hyperbole and used as gestural enactments). At last, very much like what was observed by McNeill (2005, 2012), we note that the C-VPT iconic has to present features of exaggeration (large size, tension of the hands, two-handedness, movement repetition...) to convey hyperbolic meaning.

\section{Conclusion}

Hyperbole is a figure of speech by which speakers present an exaggerated version of reality (quantitatively or qualitatively, towards positive or negative values) thus shifting frames in 
discourse to enter a fictitious representation of the world. Listeners then have a choice of rejecting the shift in footing introduced by hyperbolic speech (by verbal challenge or simple return to the previous frame), or align with speakers with laughter and/or personal contribution. In order to open a new discourse frame with hyperbole, speakers have recourse to various semantic and syntactic devices, some of which were presented in the literature: use of Extreme Case Formulations (Pomerantz, 1986), semantic changes, as well as complex modification and polysyndeton in syntax (McCarthy and Carter, 2004; Norrick, 2004), to which we can add changes in the structure of the expected predicate or aspects of the predication.

Hyperbole, as a stance-taking device, opens up a new focus of attention (Grosz and Sidner, 1986) on some object of discourse, which has to be re-analyzed in a new perspective by listeners, because of the distortion it introduces between speakers' discourse and listeners' representations of the world. In a video corpus of conversational English, it was shown that participants mark the unexpected shift of footing in hyperbole with specific prosodic and gestural patterns. The emphasis created in terms of information structure is reflected in prosody and gesture with the use of focalization devices: phonemic rhythmicity, focalization pauses, emphatic stresses, and eyebrow raises. Prosodic patterns and gestures do not however only reinforce verbal emphasis, they may fully contribute to the emphasis in a complementary way, and even constitute hyperbolic communicative acts by themselves, introducing shifts in frames (Tannen and Wallat, 1987). It was also shown that there are preferred patterns in between the conventionality scale of verbal hyperbole and some prosodic and gestural patterns: the more creative the hyperbole, the greater embodiment in terms of prosody and gesture is shown by the speaker. This conventionality scale is in direct accordance with McNeill's continuum of communicative dynamism $(2005,2012)$ and reveals once again the tight link which exists between verbal expression, prosody and gesture, advocating a single communication system.

At last, I would like to say a quick word on the context of production of hyperbolic speech. McCarthy and Carter (2004) note that hyperbole is produced in many conversational contexts and even in various discourse genres. However, Korobov and Bamberg (2004) note that caricature (which can be understood as some form of hyperbole) is used by teenagers as a way of positioning their selves and constructing their maturity. Claridge (2010) also notes that teenagers produce more hyperboles (as well as women, who will not be discussed here). Yet, the difference between these speakers and others was not as blatant as she had initially expected. The question therefore is whether hyperbole can be considered as an indicator of identity element 'young' (Norris, 2011). The corpus on which the present study is based is a small one to make any premature generalization and the speakers are post-adolescents rather than teenagers, but their discourse is nevertheless quite typical of young people. The tendencies which emerge from this corpus of conversational speech is that out of the 8 speakers involved in the recordings, although all speakers produce ECFs in equal proportions, only 4 of them produce other cases of hyperbole: Michelle, Zoe, Kate, and Tom. This cannot be explained by the fact that they speak more than their co-participant in the dialogue: in the Kate-Beth interaction, for instance, Kate utters 2863 words and Beth, 3008. This means that although Beth speaks more than Kate in the interaction, Kate produces more shifts of footing and frame. Things work differently in the Tim-Tom interaction, since Tom speaks more than Tim, and also produces more hyperboles. It seems then that with hyperbole, participants are engaged in the 'intersubjective construction of identity within local interactional contexts' (Bucholtz and Hall, 2005: 586), rather than revealing any macro-level demographic categories like 'age', and that speakers choose different strategies to do so. 


\section{Acknowledgements}

I would like to thank the participants of the dialogues as well as the students who kindly contributed to the ENVID corpus used in this study. I am also particularly indebted to an anonymous reviewer and to David McNeill for his very enlightening comments on a previous version of the paper, especially on communicative dynamism as well as its prosodic and gestural materialization.

\section{References}

Bigi B., 2012. SPPAS: a tool for the phonetic segmentations of Speech, In Proceedings of LREC 2012, Eighth International Conference on Language Resources and Evaluation, Istanbul, Turkey, [On CD-Rom].

Birdwhistell, R., 1970, Kinesics and context. University of Pennsylvania Press, Philadelphia.

Boersma, P., Weenink, D., 2009. Praat: doing phonetics by computer (Version 5.1.05) [Computer program]. Available: Retrieved May 1, 2009, from http://www.praat.org/

Bucholtz, M., Hall, K., 2005. Identity and interaction: a sociocultural linguistic approach. Discourse Studies 7, 585-614.

Cano Mora, L., 2004. At the Risk of Exaggerating: How do Listeners React to Hyperbole? Anglogermanica Online 2003-2004, 13.25.

Cano Mora, L., 2009. All or Nothing: A Semantic Analysis of Hyperbole. Revista de Lingüística y Lenguas Aplicadas 4(1), 25-35.

Caudal, P., Nicolas, D., 2005. Types of degrees and types of event structures. In: C. Maienborn \& A. Wöllstein (Eds.), Event Arguments: Foundations and Applications. Niemeyer, Tübingen, 277-300.

Christodoulidou, M., 2011. Hyperbole in Everyday Conversation. In Proceedings of 19th International Symposium on Theoretical and Applied Linguistics, Thessaloniki, Greece, 143-152.

Claridge, C., 2010. Hyperbole in English. A Corpus-based Study of Exaggeration. CUP, Cambridge.

Colston, H.L., Keller, S.B., 1998. You'll Never Believe This: Irony and Hyperbole in Expressing Surprise. Journal of Psycholinguistic Research 27(4), 499-513.

Ducrot, O., 1980. Les échelles argumentatives. Les Editions de Minuit, Paris.

Ferré, G., 2003. Discursive, Prosodic and Gestural Marking of Focalization Pauses in British English. In Proceedings of Interfaces Prosodiques, Nantes, France, 265-270.

Ferré, G., 2004. Degrés d'intensité exprimés à l'oral. Du discours à la gestualité en passant par la prosodie. In Proceedings of Travaux Linguistiques du Cerlico, 17 : "Intensité, comparaison, degré”, Rennes, 13-26.

Ferré, G., 2011. Thematisation and Prosodic Emphasis in Spoken French. A Preliminary Analysis. In Proceedings of Gespin, Bielefeld, Germany, [on CD-Rom].

Ferré, G., 2014. A Multimodal Approach to Markedness in Spoken French. Speech Communication 57, 268-282.

Fraser, B., 1999. What are discourse markers? Journal of Pragmatics 31, 931-952.

Grosz, B.J., Sidner, C.L., 1986. Attention, Intention, and the Structure of Discourse. Computational Linguistics 12(3), 175-204.

Herrero Ruiz, J., 2008. Overstatement \& cognitive operations. In: R. Monroy \& A. Sánchez (Eds.), 25 Años de Lingüística en España: Hitos y Retos / 25 Years of Applied Linguistics in Spain: Milestones and Challenges. Edit.um, Murcia, 791-797. 
Israel, M., 2006. Saying Less and Meaning Less. In: B. Birner \& G. Ward (Eds.), Drawing the Boundaries of Meaning: Neo-Gricean Studies in Pragmatics and Semantics in Honor of Laurence R. Horn. John Benjamins, Amsterdam \& Philadelphia, 143-162.

Kendon, A., 2004. Gesture. Visible Action as Utterance. CUP, Cambridge.

Kennedy, C., 2002. The Landscape of Vagueness. Unpublished manuscript. Northwestern University, Michigan. October 1, 2002.

Korobov, N., Bamberg, M., 2004. Positioning a 'mature' self in interactive practices: How adolescent males negotiate 'physical attraction' in group talk. British Journal of Developmental Psychology 22, 471-492.

Krahmer, E., et al., 2002. Pitch, Eyebrows and the Perception of Focus. In Proceedings of Speech Prosody 2002, Aix-en-Provence, 443-446.

Krahmer, E., Swerts, M., 2007. The Effects of Visual Beats on Prosodic Prominence: Acoustic Analyses, Auditory Perception and Visual Perception. Journal of Memory \& Language 57(3), 396-414.

McCarthy, M., Carter, R., 2004. "There's millions of them': hyperbole in everyday conversation. Journal of Pragmatics 36, 149-184.

McNeill, D., 1992. Hand and Mind: What Gestures Reveal about Thought. The University of Chicago Press, Chicago \& London.

McNeill, D., 2005. Gesture and Thought. The University of Chicago Press, Chicago \& London.

McNeill, D., 2012. How Language Began. Gesture and Speech in Human Evolution. Cambridge University Press, Cambridge.

Norrick, N.R., 2004. Hyperbole, extreme case formulation. Journal of Pragmatics 36, $1727-$ 1739.

Norris, S., 2011. Identity in (Inter)action. Introducing Multimodal (Inter)action Analysis. Mouton de Gruyter, Berlin \& New York.

Pierrehumbert, J., Hirshberg, J., 1990. The Meaning of Intonational contours in the Interpretation of Discourse. In: P. Cohen, et al. (Eds.), Intentions in Communication. MIT Press, Cambridge MA, 271-311.

Pomerantz, A., 1986. Extreme Case formulations: A way of legitimizing claims. Human Studies 9, 219-229.

Prévost, S., 2003. Détachement et topicalisation : des niveaux d'analyse différents Cahiers de Praxématique 40, 97-126.

Sacks, H., et al., 1974. A Simplest Systematics for the Organization of Turn-Taking for Conversation. Language 50(4), part 1, 696-735.

Sapir, E., 1944. Grading, A Study in Semantics. Philosophy of Science 11, 93-116.

Selkirk, E., 1995. Sentence prosody: intonation, stress, and phrasing. In: J.A. Goldsmith (Ed.), The Handbook of Phonological Theory. Blackwell, Cambridge, MA, \& Oxford, UK, 550569.

Sert, O., 2008. An Interactive Analysis of Hyperboles in a British TV Series: Implications For EFL Classes. ARECLS: Annual Review of Education, Communication, and Language Sciences 5, 1-28.

Swerts, M., Krahmer, E., 2008. Facial expression and prosodic prominence: Effects of modality and facial area. Journal of Phonetics 36, 219-238.

Tannen, D., Wallat, C., 1987. Interactive Frames and Knowledge Schemas in Interaction: Examples from a Medical Examination/Interview. Social Psychology Quarterly 50(2), 205-216.

Wee, L., 2004. 'Extreme communicative acts' and the boosting of illocutionary force. Journal of Pragmatics 36, 2161-2178. 
Wells, J.C., 1997. SAMPA computer readable phonetic alphabet. In D. Gibbon, R. Moore, and R. Winski (Eds.), Handbook of Standards and Resources for Spoken Language Systems. Mouton de Gruyter, Berlin \& New York, Part IV, section B.

Wells, J.C., 2006. English Intonation. An Introduction. CUP, Cambridge.

Wittenburg, P., et al., 2006. ELAN: a Professional Framework for Multimodality Research. In Proceedings of LREC 2006, Fifth International Conference on Language Resources and Evaluation, Genoa, Italy, [On CD-Rom]. 